\title{
Familial tumoral calcinosis
}

INSERM

\section{Source}

INSERM. (1999). Orphanet: an online rare disease and orphan drug data base. Familial tumoral calcinosis. ORPHA:53715

Tumoral calcinosis is a phosphocalcic metabolism anomaly, particularly among younger age groups and characterized by the presence of calcified masses in the juxta-articular regions (hip, elbow, ankle and scapula) without joint involvement. Histologically, lesions display collagen necrobiosis, followed by cyst formation and a foreign-body response with calcification Two forms of tumoral calcinosis have been described: normocalcemic tumoral calcinosis and familial tumoral calcinosis. 